University of Wollongong

Research Online

Faculty of Social Sciences - Papers (Archive) Faculty of Arts, Social Sciences \& Humanities

2016

Public Report: Case Study of White Ribbon Australia's Ambassador

Program: Men as Allies to Prevent Men's Violence against Women

Kenton Bell

University of Wollongong, kb759@uowmail.edu.au

Claire Seaman

University of Wollongong, ces660@uowmail.edu.au

Follow this and additional works at: https://ro.uow.edu.au/sspapers

Part of the Education Commons, and the Social and Behavioral Sciences Commons

Research Online is the open access institutional repository for the University of Wollongong. For further information contact the UOW Library: research-pubs@uow.edu.au 


\title{
Public Report: Case Study of White Ribbon Australia's Ambassador Program: Men as Allies to Prevent Men's Violence against Women
}

\author{
Abstract \\ This project is a case study of White Ribbon Australia's Ambassador Program. This project was \\ independently conducted by Kenton Bell and Claire E. Seaman, under the auspices of the University of \\ Wollongong and supervised by Associate Professor Michael Flood and Associate Professor Richard \\ Howson. Through in-depth interviews and an online survey, this project investigated how and why men \\ become part of the Ambassador Program; how they enact their role as an ally to end men's violence \\ against women, the challenges they encounter, and how they overcome them. The project has two \\ primary aims. First, to provide an independent assessment of the Ambassador Program through analysis \\ of Ambassador perceptions of White Ribbon Australia's successes and areas for improvement, and to \\ create an Ambassador demographic profile. Second, due to the scale of the research and the position of \\ White Ribbon Australia as a leader in engaging men to prevent men's violence against women, the case \\ study aims to inform at a broader social level. It seeks to provide insight into Ambassadors' motivations \\ and experiences which may assist other organisations in Australia and around the world to similarly \\ engage men in preventing men's violence against women.
}

\section{Keywords}

men, program:, ambassador, ribbon, white, against, study, women, case, report:, public, allies, prevent, men's, violence, australia's

\section{Disciplines \\ Education | Social and Behavioral Sciences}

\section{Publication Details}

Bell, K. \& Seaman, C. E. (2016). Public Report: Case Study of White Ribbon Australia's Ambassador Program: Men as Allies to Prevent Men's Violence against Women. Wollongong, Australia: University of Wollongong. 


\title{
Public Report
}

\section{Case Study of White Ribbon Australia's Ambassador Program: Men as Allies to Prevent Men's Violence against Women}

\author{
Researchers: Kenton Bell and Claire E. Seaman \\ University of Wollongong \\ Corresponding Author: Kenton Bell, email: kb759@uowmail.edu.au \\ Date: $27 / 09 / 2016$
}

\section{Project Overview}

This project is a case study of White Ribbon Australia's Ambassador Program. This project was independently conducted by Kenton Bell and Claire E. Seaman, under the auspices of the University of Wollongong and supervised by Associate Professor Michael Flood and Associate Professor Richard Howson.

Through in-depth interviews and an online survey, this project investigated how and why men become part of the Ambassador Program; how they enact their role as an ally to end men's violence against women, the challenges they encounter, and how they overcome them.

The project has two primary aims. First, to provide an independent assessment of the Ambassador Program through analysis of Ambassador perceptions of White Ribbon Australia's successes and areas for improvement, and to create an Ambassador demographic profile. Second, due to the scale of the research and the position of White Ribbon Australia as a leader in engaging men to prevent men's violence against women, the case study aims to inform at a broader social level. It seeks to provide insight into Ambassadors' motivations and experiences which may assist other organisations in Australia and around the world to similarly engage men in preventing men's violence against women.

\section{Recommendations to White Ribbon Australia}

These recommendations have been made from both the survey and interview data.

\section{Ambassadorship}

From the interviews, Ambassadors felt strongly about maintaining the legitimacy of the Ambassador Program. Thus, the position of Ambassador should be limited and granted solely to those men who have proven (and continue to prove) their commitment to the mission of White Ribbon Australia, and when men fail in this commitment, their Ambassadorship is removed.

\section{Diversity}

Responses indicate that Ambassadors are overwhelmingly socioeconomically advantaged, and collectively, they are an immense resource. It also indicates that further work should be done to achieve greater diversity in the program to spread the anti-violence message more effectively. Having an Ambassador community that embodies a diverse and progressive range of masculine identities is vital in moving towards what White Ribbon Australia's recently released Strategic Vision (2016-2019) calls a 'new vision of masculinity' (see Key Findings: 1). 


UNIVERSITY
OF WOLLONGONG
AUSTRALIA

\section{Communication}

A monthly, regionally directed email newsletter solely for Ambassadors from White Ribbon Australia needs to be implemented. The newsletter should comprise key points outlining White Ribbon Australia programs, new research, and updates on events in their area. Additionally, this newsletter should include helpful tips and information on preventing men's violence against women. For example, methods to engage with men such as the bystander approach, links to useful resources, and a section highlighting 'less famous' Ambassadors (see Key Findings: 4, 6).

\section{Fatherhood}

White Ribbon Australia should focus more on family and fatherhood to engage the Ambassadors and the broader community. During the interviews, Ambassadors repeatedly discussed their children as motivators for their involvement, often seeking to ensure that their children did not encounter the pain they had experienced as children (see Key Findings: 1, 2).

\section{Integration}

As indicated by Ambassadors in the survey and interviews, White Ribbon Australia should seek to collaborate more closely with other anti-violence organisations. The Ambassadors can assist in building stronger relations with other violence prevention organisations and women's groups (see Key Findings: 6).

\section{Motivation}

The Ambassadors surveyed and interviewed do not necessarily work to prevent men's violence against women because of White Ribbon Australia. Instead, the organisation is a platform—-many Ambassadors were doing the work both formally and informally, long before the organisation existed and would continue to do so if White Ribbon Australia disappeared. Many of the Ambassadors have knowledge and experience in the anti-violence area and large amounts of social capital (whom they know) and cultural capital (what they know) that are coupled with conviction, and these men need to be utilised to help train other Ambassadors (see Key Findings: 3, 6).

\section{Reflection}

From the interviews, it became apparent that the Ambassadors appreciated the opportunity to reflect on their role as men preventing men's violence against women. Men involved in the campaign should have opportunities for critical reflection regarding masculinity, gender, and violence, through discussion groups or education sessions, to inspire both personal change and collective action. These opportunities for reflection should be included in Regional Forums, Regional Committees, or the monthly newsletter and can be facilitated by other knowledgeable Ambassadors (see Key Findings: 5).

\section{Regional Committees}

Most of the respondents want local White Ribbon Australia committees and working groups to facilitate planning of events, resource exchange, and networking opportunities - including low or no-cost monthly meetings. These committees can provide information about preventing men's violence against women, further opportunities for participation, and networking with other Ambassadors to increase solidarity while improving resource utilisation (see Key Findings: 4). 


UNIVERSITY
OF WOLLONGONG
AUSTRALIA

\section{Resource Mobilisation}

Ambassadors report needing information, opportunity, and networking to improve the effectiveness of their efforts. Additionally, Ambassadors feel underutilised in general and specific to their unique skill sets. The resource pool among the Ambassadors is immense and must be identified and harnessed in working to prevent men's violence against women in Australia (see Key Findings: 1, 3, 4, 6).

\section{Transparency}

White Ribbon Australia should send a single email to all Ambassadors highlighting these research findings, and a follow-up responding to the research. During the interviews, Ambassadors reacted positively to being asked their opinion and are eager for a response from both the researchers and White Ribbon Australia. This research is a critical opportunity for White Ribbon Australia to acknowledge the previous issues regarding the Ambassador Program and discuss any changes moving forward.

\section{Method}

\section{Data Collection}

This research was completed using data obtained through an online survey and from in-depth interviews. Given the breadth of the aims of this study, the primary source of data for this report is the survey. The survey data is further contextualised by the interviews, which provide rich insight into lived experiences through narrative.

An opportunity to participate was sent, via email, to all White Ribbon Australia's Ambassadors in September 2015. From the 2062 emails sent, 296 online surveys were sufficiently completed, and 86 Ambassadors participated in an in-depth interview. Through the Ambassadors' insights, this research project will help inform the future direction of the Ambassador Program.

\section{Ethics Approval}

The Human Research Ethics Committee at the University of Wollongong approved all research procedures employed in this study. Approval number: HE14/451.

\section{Data Analysis}

For the survey, open-ended responses were recoded with both researchers reviewing the themes and data to ensure consistency. Descriptive statistics are presented as proportions of the total 296 Ambassadors surveyed. Recoding of responses to questions, including the creation of larger, composite demographic categories, was also undertaken to maximise the usability of responses and to maintain the confidentiality of respondents. In examining the Ambassador's characteristics, comparisons were made to the most recent available Australian Census data (2011) where equivalent categories could be ascertained. Differences are reported as significant with an alpha level set at .05. All interviews were recorded digitally, de-identified (i.e., names, locations, and ages were changed), and transcribed. Interview data was thematically analysed and serves a complementary function in this report. The key findings are presented below. Results are interpreted through the theoretical lens of social movement theory, particularly concerning resource mobilisation. 


\section{Key Findings}

\section{Demographics}

- Ambassadors surveyed reported a mean length of involvement of 4 years, with a median length of involvement of 3.6 years.

- Ambassadors are just as likely to come from regional and remote areas (excluding very remote areas) as the broader male population in Australia but are slightly less likely to come from city areas.

- The mean age of Ambassadors is 50.6 years of age. This is significantly older than the mean age of adult males in Australia (46.1 years), as well as the mean age of adult male volunteers (47.8 years).

- Ambassadors identified overwhelmingly as heterosexual and were significantly more likely than males in Australia to be married and have children.

- There is a significant, distinct lack of religiosity amongst the Ambassadors compared to the broader male population in Australia.

- Overall, Ambassadors surveyed identified across the 'left-right' political spectrum, although more identified towards the political 'left', and none identified in the furthest 'right' category (see Figure 1).

Figure 1. In politics people sometimes refer to being on the left or on the right. Where would you place yourself on a scale from 0 to 10 where 0 means left and 10 means right?

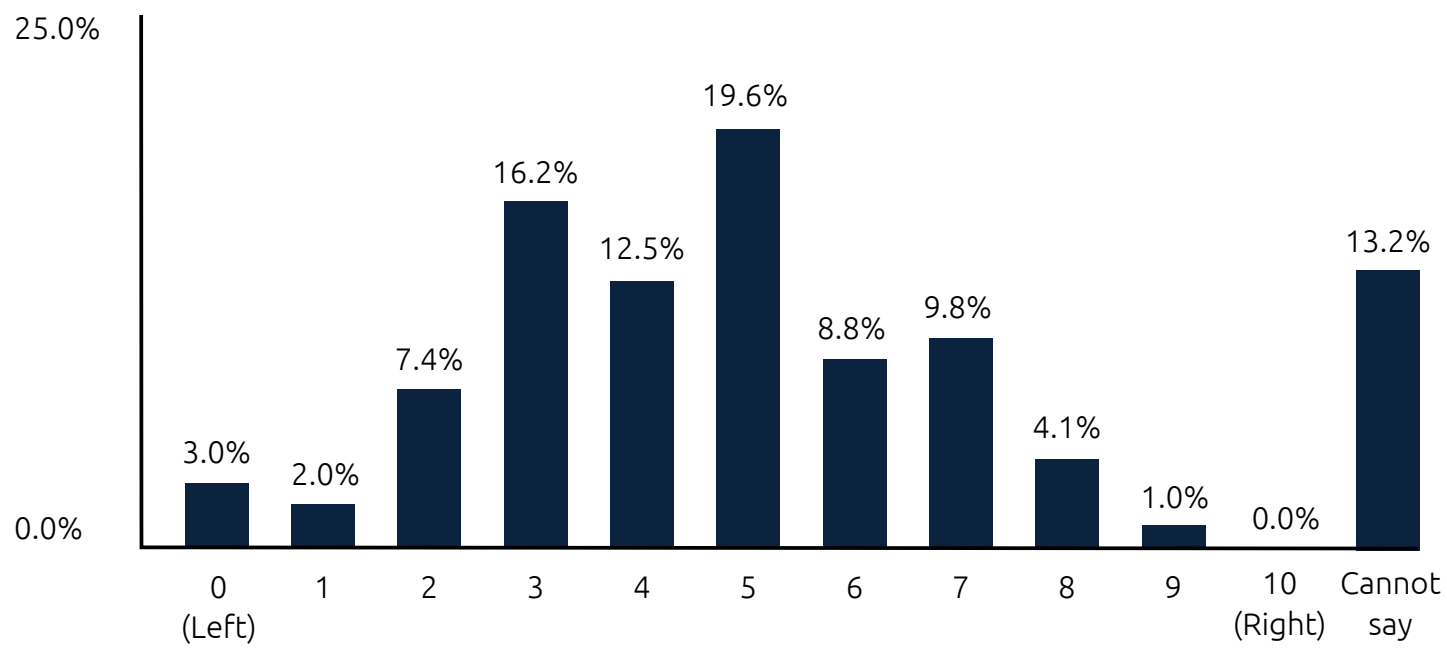

-While Ambassadors reported comparable levels of employment to the broader male population, they do have significantly higher levels of formal education, and they are significantly more likely to be in higher income brackets relative to full-time adult male workers (see Figure 2). The relatively higher incomes of Ambassadors were not accounted for by increases in the wage price index since 2011. Only a small minority of Ambassadors reported being employed in occupations that could be classified as 'blue collar' work (e.g., Labourers, Machinery Operators and Drivers, Technicians and Trades Workers), according to Australian Bureau of Statistics' classifications. 


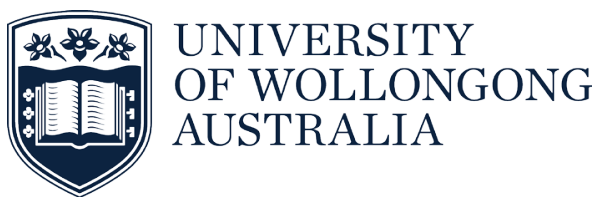

Figure 2. What is your gross annual income, before tax or other deductions, from all sources? (condensed categories)

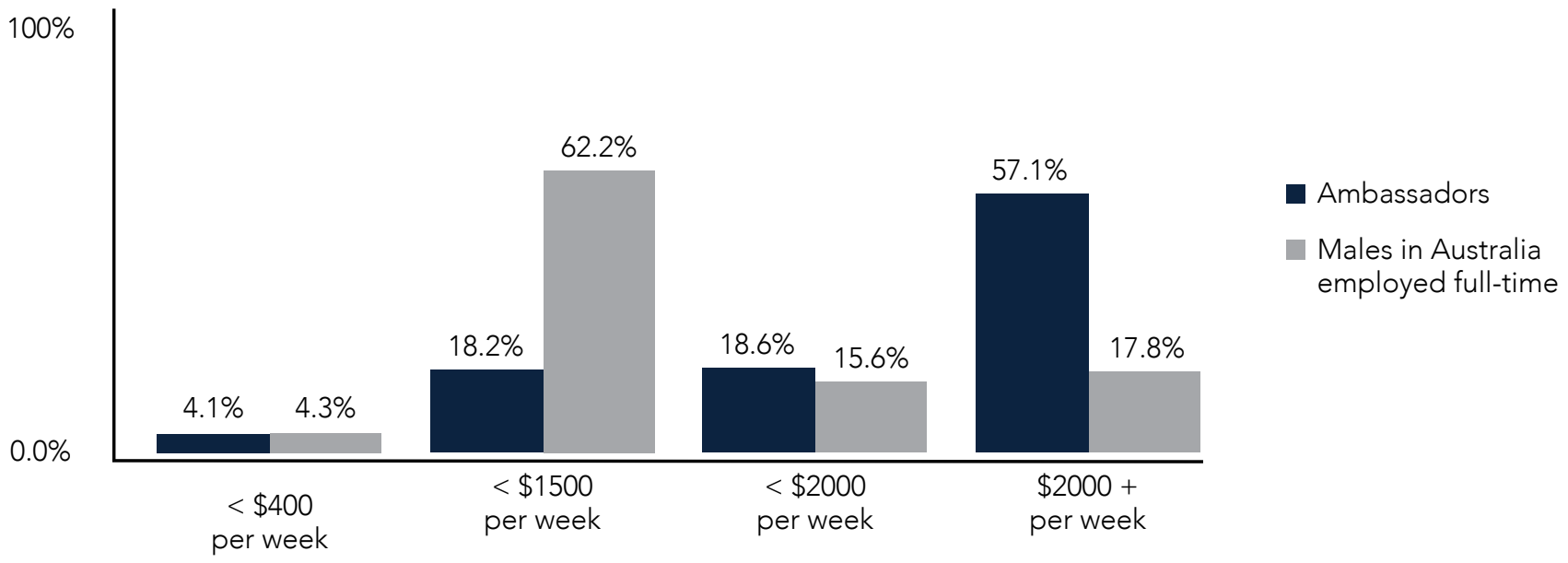

\section{Why Men become White Ribbon Australia Ambassadors}

- Most Ambassadors surveyed initially heard about White Ribbon Australia through their workplace or the White Ribbon Australia Workplace Accreditation program.

- Ambassadors indicated they primarily became part of White Ribbon Australia 'to make a difference in their community' (75.7\%), due to 'moral obligation' (69.6\%), because they 'heard stories related to men's violence against women' (53.7\%), and because they had 'learned statistics related to men's violence against women' (43.2\%) (see Appendix: Figure A1).

- From the interviews, the role of fatherhood as a catalyst for initial involvement is apparent and provides opportunities for meaning making.

3. Ambassador Contributions to White Ribbon Australia and White Ribbon Australia's Contributions to Ambassadors

- The Ambassadors surveyed indicated that they believed their primary contributions to White Ribbon Australia are raising awareness of the issue with others (54.7\%), raising awareness in their workplaces (26.7\%), speaking at events as an Ambassador (19.9\%), and running White Ribbon Australia events or being on White Ribbon Australia committees (14.2\%).

- Half (49.7\%) of Ambassadors surveyed had attended a White Ribbon Australia event in the last twelve months, while a majority had worn the White Ribbon Australia pin, bracelet or t-shirt (78.4\%) or discussed men's violence against women with friends or family $(79.4 \%)$ during this time.

- When asked about their knowledge of White Ribbon Australia programs, the surveyed Ambassadors had the most limited knowledge of the Diversity Program, with $48.3 \%$ only knowing 'the name' or not being familiar 'at all' with the Diversity Program. This finding is larger than the proportion of Ambassadors who 'only knew the name' or were not familiar 'at all' with the Breaking the Silence Schools Program (26.0\%), and the Workplace Accreditation Program (20.3\%). 


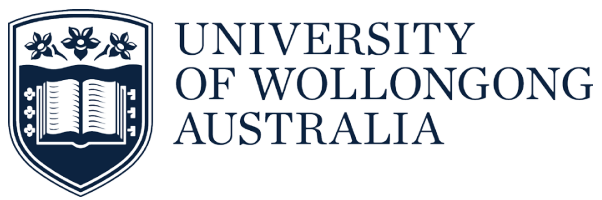

- Common themes regarding what Ambassadors feel White Ribbon Australia provides them with to help prevent men's violence against women are information such as resources and research (51.7\%), opportunity such as a platform, means, or purpose (24.3\%), legitimacy through the White Ribbon Australia brand or the title of Ambassador (16.9\%), and support and encouragement (14.9\%).

\section{Experiences, both Positive and Challenging, Commonly Encountered by White Ribbon Australia Ambassadors}

- The positive experiences of Ambassadorship are an increased knowledge of men's violence against women, specifically (75.0\%) and violence against women in general (72.0\%). Other positive experiences include helping to 'reduce or prevent men's violence against women' (56.1\%); 'increased confidence to stand up for what I believe in' (55.1\%); a 'sense of purpose' (50.7\%); and a 'sense of personal fulfillment' (49.7\%) (see Appendix: Figure A2).

- The Ambassadors reported that 'not being utilised properly' (24.3\%); 'lack of year-round involvement' (21.6\%); and a 'lack of a "grassroots" feel' (19.9\%) were key challenges. However, the primary challenge encountered by Ambassadors is a 'lack of time' (36.5\%), while one-quarter (24.7\%) of the Ambassadors indicated 'no challenges faced' (see Appendix: Figure A3).

- From the interviews, Ambassadors want to do more - not less - and often lament the lack of opportunities out side of White Ribbon Day and White Ribbon Night.

- Most Ambassadors reported feeling underutilised by White Ribbon Australia not only in general but specific to their unique skill sets. While this finding is apparent from the survey, this was repeatedly found in the interviews. Law Enforcement Officers, Social Workers, and Counsellors indicated they had skills and the desire to serve, but no outlet.

- These challenges can be summarised as a lack of proper utilisation, isolation from other Ambassadors, and a lack of confidence to make a change.

\section{Effect of White Ribbon Australia involvement on Ambassadors' Lives}

\subsection{Changes in Relationships with Women}

- Over one-third of Ambassadors surveyed (39.5\%) report that being an Ambassador had changed how they relate to women (see Figure 3).

- Of the Ambassadors who indicated that they had changed how they relate to women, $86.3 \%$ are 'more conscious' of what they say and how they say it, while $84.6 \%$ are 'more conscious of promoting equality and equity' in both their personal and professional lives (see Appendix: Figure A4).

- Of the Ambassadors who report they had not changed how theyrelate to women, $73.7 \%$ provided extended responses indicating they already respected women or believed in equality and equity.
Figure 3. Has being an Ambassador changed how you relate to women?

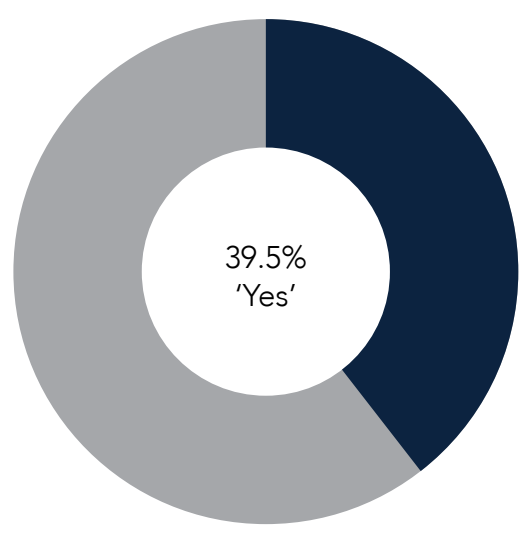




UNIVERSITY
OF WOLLONGONG
AUSTRALIA

\subsection{Changes in Relationships with other Men}

- Most Ambassadors surveyed (68.6\%) report that their involvement with White Ribbon Australia has changed how they relate to men (see Figure 4).

- Of the Ambassadors who indicated they had changed how they relate to men, nine tenths (89.2\%) were 'more likely to challenge sexist behaviour toward women' (see Appendix: Figure A5).

- Of the Ambassadors that reported they had not changed how they relate to men, one-third (34.4\%) provided extended responses indicating they were always clear where they stood on men's violence against women to other men or had spoken against men's violence against women, and one-third (30.1\%) reported having always had respectful relationships with men and other people in general.
Figure 4. Has being an Ambassador changed how you relate to other men?

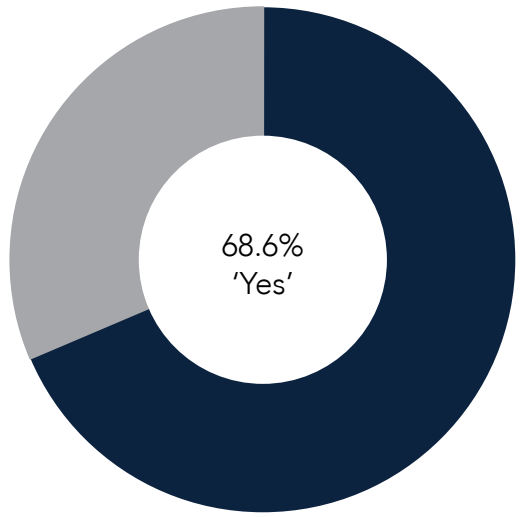

\subsection{Changes in the Meaning of being a Man}

- When asked whether being involved with White Ribbon Australia had changed their view of what it means to be a man, three-quarters $(74.7 \%)$ reported they are 'more aware of the need for positive male role models'.

- Half placed more 'emphasis on promoting gender equality and equity' in their personal life (49.7\%) and professional life (49.0\%). Finally, almost half of the Ambassadors surveyed 'question the notion of "boys will be boys"' (47.6\%) and have increased their 'ability to self-reflect' as men (45.9\%) (see Appendix: Figure A6).

\section{White Ribbon Australia Successes and Areas for Improvement, and Ways to Increase or Sustain Ambassador Involvement}

\subsection{Successes}

- The vast majority (91.6\%) of Ambassadors surveyed indicated that 'creating a "brand" that helps promote an anti-violence message' is a primary success of White Ribbon Australia. Other significant successes include 'enabling men to speak to men about stopping men's violence against women' (83.1\%), 'spreading awareness of men's violence against women' (79.7\%), and 'increasing male engagement in anti-violence initiatives' (77.4\%) (see Appendix: Figure A7).

- The successes that received the lowest response were 'working with diverse communities to increase awareness and engagement' (29.1\%) and 'working with other anti-violence organisations' (24.7\%).

\subsection{Areas for Improvement}

- When asked about areas of improvement for White Ribbon Australia, Ambassadors nominated 'better communication between Ambassadors near each other' (59.5\%) and 'better use of each Ambassadors' unique skill sets' (49.0\%) as the top areas of concern.

- The Ambassadors also recommend better integration with both 'local support services' (39.9\%) and 'women's groups' (34.8\%) (see Appendix: Figure A8). 


\section{UNIVERSITY OF WOLLONGONG AUSTRALIA}

\subsection{Increasing or Sustaining Ambassador Involvement}

- The key methods Ambassadors recommend to increase or sustain their involvement are 'year-around opportunities' (46.6\%); 'training opportunities' (40.5\%); 'opportunities to assist other Ambassadors' (37.8\%); and 'more suggestions and guidelines for activities' (37.5\%) (see Appendix: Figure A9).

\section{Limitations}

This is a case study has provided unique insight into the experiences, motivations, and challenges of White Ribbon Australia Ambassadors. However, the authors note that there are some limitations in the generalisability of results. Primarily, as is common with surveys, the representativeness of this study is limited by the self-select nature of the design. For instance, the results may reflect social network clusters of Ambassadors (e.g., Ambassadors from the same workplace), and it is likely the Ambassadors who agreed to participate were the most motivated to do so. Although sample bias could not be checked for, there was no evidence of an attrition bias among incomplete surveys. The Ambassador population was in flux during the research window as White Ribbon Australia was going through corporate restructuring and the Ambassador Program was being overhauled, with each potential participant being asked to recommit concurrently to the organisation.

Inferential statistical tests were applied under the assumption that the 2011 Australian Census data remained representative of true population parameters at the time the survey was administered (2015), and that the Ambassador sample is representative of the Ambassador population despite the non-random sampling method. It should be noted, however, that all Ambassadors were invited to participate and that the sample obtained therefore comprises a relatively large proportion of the population of interest. This research is the most comprehensive of its kind to date given the survey and interview response, and overall scope and intention. It provides rich insight into the background and experiences of Ambassadors, as they work under the Ambassador Program, contributing to the broader social movement of preventing men's violence against women.

\section{Additional Research Outcomes}

\section{Reports}

In addition to this report, there was an exhaustive Internal Research Report presented to White Ribbon Australia's staff and board. Due to the sensitive nature of the data, particularly demographic information, portions of this report will not be released to the public.

\section{Presentations and Papers}

A series of academic articles are planned from the research findings. Additionally, the research findings will be disseminated to the public through a series of articles and discussions via broadcast, print, and online media. The goal has always been to create awareness about men's violence against women while researching applied and practical ways to stop it. Because of this, the findings will be presented as broadly as possible, including at Regional Committees and Regional Forums. 


\section{Future Research}

This research was a pilot study. Based on the work completed with White Ribbon Australia the survey and interview schedule has been changed to reflect what worked and what did not. The intention is to replicate this study with other White Ribbon organisations and similar organisations around the world for cross-cultural analysis. These efforts will create a research instrument that others can use to investigate male allyship in relation to men's violence against women and improve programming within their organisation.

\section{Recommended Citation}

Bell, Kenton and Claire E. Seaman. 2016. 'Public Report: Case Study of White Ribbon Australia's Ambassador Program: Men as Allies to Prevent Men's Violence against Women'. Wollongong: University of Wollongong. doi: $10.6084 / \mathrm{m} 9$. figshare. 3826764

\section{Author Biographies}

\section{Kenton Bell}

Kenton is a postgraduate student at the University of Wollongong in the Department of Humanities and Social Inquiry. Kenton's professional objectives are teaching sociology specialising in Men and Masculinities; Teaching and Learning; and Law and Society while researching solutions-oriented approaches to preventing violence. Additionally, he is the editor of the Open Education Sociology Dictionary, available at http://SociologyDictionary.org.

\section{Claire E. Seaman}

Claire is a PhD candidate at the University of Wollongong in the Department of Humanities and Social Inquiry. Claire's research interests include Well-being and the Life Course; Gender Studies; and Work and Employment. Beyond her research, Claire enjoys teaching Social Research Methods with a focus on statistics.

This work is released under a $\underline{\underline{\text { Creative Commons Attribution } 4.0 \text { International License. }}}$ 


\begin{tabular}{|l|l} 
UNIVERSITY \\
OF WOLLONGONG \\
AUSTRALIA
\end{tabular}

\section{Appendix}

Figure A1: Why did you become involved in White Ribbon Australia? (multiple response item)

Fixed choice option _ Themes identified from "Other" responses

To make a difference in my community - $75.7 \%$

Moral obligation $-69.6 \%$

Heard stories related to men's violence against women - $53.7 \%$

Learned statistics about men's violence against women - $43.2 \%$

To positively change how my family and friends treat women - 36.8\%

Domestic or sexual violence committed against someone you know - 33.4\%

Influenced or invited by other men to join - $27.7 \%$

Influenced or invited by women to join - $24.0 \%$

Invited to join by White Ribbon Australia - 23.0\%

Domestic or sexual violence committed by someone you know - 15.9\%

To use the White Ribbon name recognition as resource - $12.2 \%$

Profile building at work and within my profession - $11.5 \%$

Professional directive, expectation, or request $-10.8 \%$

Networking opportunities - $7.8 \%$

Domestic or sexual violence committed against you - $6.8 \%$

Prior participation with a similar organisation $-6.1 \%$

Wanted to join a community organisation - $6.1 \%$

Domestic or sexual violence committed by you $-1.4 \%$

Other (please specify) - 12.5\%

To be a role model/provide leadership - 3.0\%

Related to my profession $-2.7 \%$

Fatherhood $-1.4 \%$

Inspired by White Ribbon Australia's work - 1.0\%

Humanist/human rights advocate/believer in equality - 1.0\%

Influence how my profession is perceived $-0.7 \%$

Compelled by/desire to work within Indgenous communities - $0.7 \%$ 
Figure A2: What are some of your positive experiences as an Ambassador? (multiple response item)
Fixed choice option
Themes identified from "Other" responses

An increased understanding of men's violence against women - $75.0 \%$

Greater knowledge of violence against women - $72.0 \%$

Helped reduce or prevent men's violence against women - $56.1 \%$

Increased confidence to stand up for what I believe in - $55.1 \%$

Sense of purpose $-50.7 \%$

Sense of personal fulfillment $-49.7 \%$

A sense of community and solidarity with other Ambassadors - 45.9\%

More equal and equitable relationships with women in my professional life - $44.3 \%$

More equal and equitable relationships with women in my personal life - $41.9 \%$

A positive change in how I am seen by friends and acquaintances - 35.5\%

Meeting other Ambassadors - 30.7\%

Becoming a better father $-30.7 \%$

Positively changing how my family and friends treat women - 27.4\%

More equal and equitable relationships with men in my professional life - $21.6 \%$

More equal and equitable relationships with men in my personal life - $20.3 \%$

Profile building at work and within my profession - $19.9 \%$

No positive experiences $-2.7 \%$

Other (please specify) - 9.8\%

Negative experiences $-1.7 \%$

The use of White Ribbon Australia as a tool/A chance to be heard/credibility - 1.7\% 


\begin{tabular}{|l|l} 
UNIVERSITY \\
OF WOLLONGONG \\
AUSTRALIA
\end{tabular}

Figure A3: What challenges have you encountered as an Ambassador? (multiple response item)

Fixed choice option $\quad$ Themes identified from "Other" responses

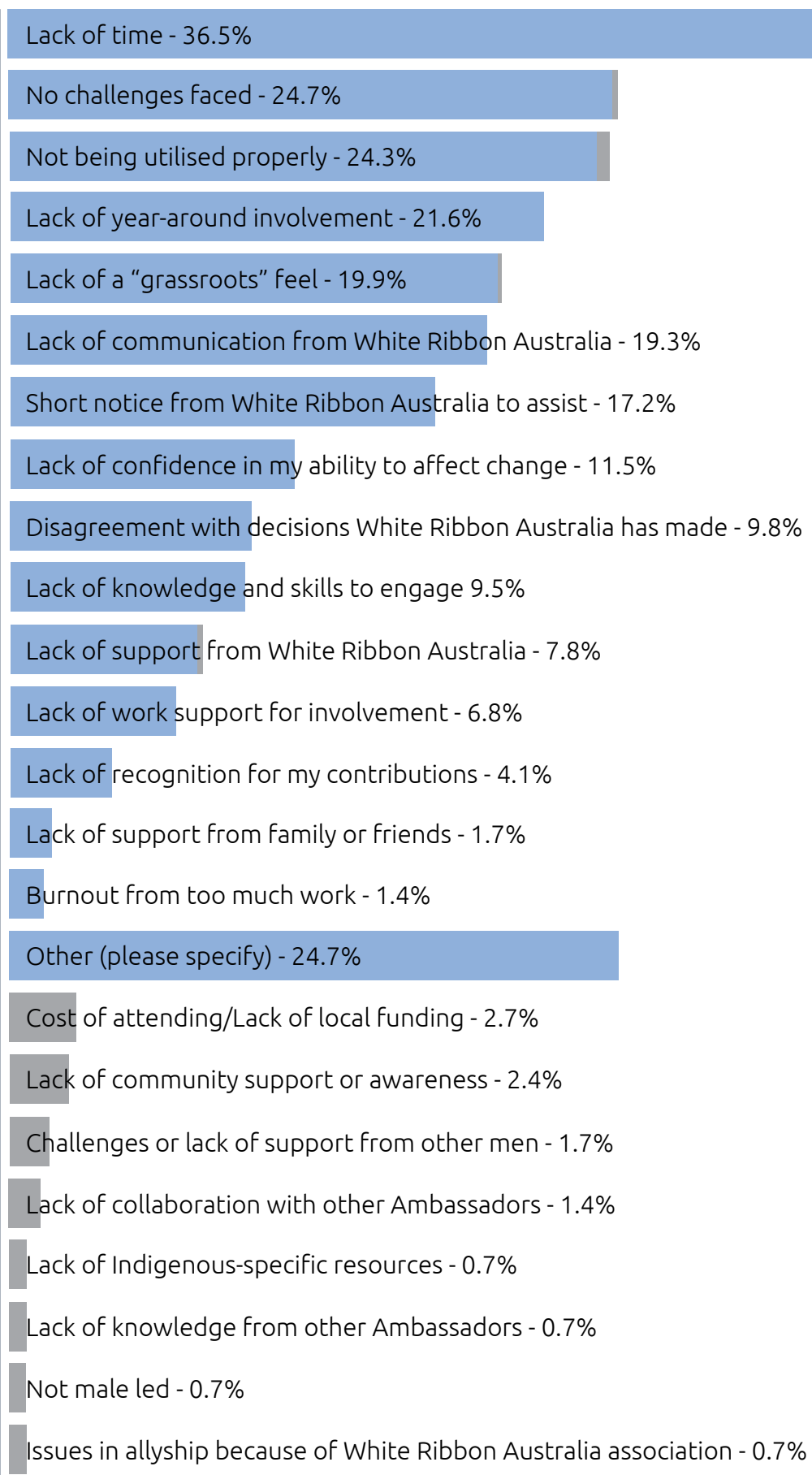




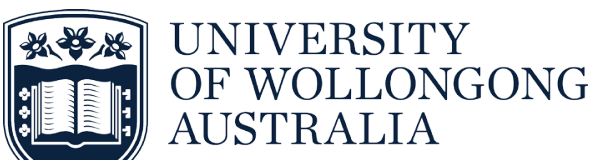

Figure A4: How has being an Ambassador changed how you relate to women? - \% of total respondents who indicated a change (multiple response item)

Fixed choice option _ Themes identified from "Other" responses

More conscious of what I say and how I say it - $86.3 \%$

More conscious of promoting gender equality and equity in my professional life $-84.6 \%$

More conscious of promoting gender equality and equity in my personal life - $84.6 \%$

More empathetic to women $-48.7 \%$

Listen more to what women have to say $-41.0 \%$

Treat women with more respect - $36.8 \%$

Other (please specify) - $8.5 \%$

Have a greater understanding of violence against women $-2.6 \%$

0

$100 \%$

Figure A5: How has being an Ambassador changed how you relate to other men? - \% of total respondents who indicated a change (multiple response item)

Fixed choice option — Themes identified from "Other" responses

I am more likely to challenge sexist behaviour toward women - 89.2\%

I have lost male friends because of my position on violence $-8.9 \%$

I am more confident in my ability to speak about mens violence against women with others - $3.4 \%$

Other (please specify) - $10.8 \%$

I am more confident in my ability to speak about violence against women with others - $3.4 \%$

More aware of sexist attitudes/behaviour $-2.0 \%$

Gained friends or grown closer to my friends - $1.0 \%$

0

$100 \%$ 


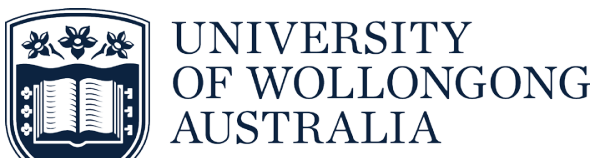

Figure A6: How has being involved in White Ribbon Australia changed your view of what it means to be a man? (multiple response item)
Fixed choice option
Themes identified from "Other" responses

I am more aware of the need for positive male role models - $74.7 \%$

More emphasis on promoting gender equality and equity in my personal life $-49.7 \%$

More emphasis on promoting gender equality and equity in my professional life $-49.0 \%$

Greater understanding of how personal attitude/behaviour impacts others - $48.3 \%$

I question the notion of "boys will be boys" - $47.6 \%$

I have an increased ability to self-reflect on my role as a man - 45.9\%

Greater understanding of how dominant ideals of masculinity have shaped my life - $33.4 \%$

I place less emphasis on proving my manliness - $22.6 \%$

It has changed what I view to be a "good" man - 20.6\%

No change $-13.9 \%$

Other (please specify) - $8.8 \%$

I more aware of the complex nature of violence against women and men relating to women - $2.0 \%$

White Ribbon Australia has put me further down the road I was already on $-1.7 \%$

I know that men can be part of preventing violence against women - $0.7 \%$ 


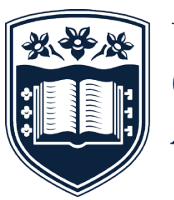

Figure A7: What do you think are the primary successes of White Ribbon Australia? (multiple response item)

Fixed choice option

Themes identified from "Other" responses

Creating a 'brand' that helps promote an anti-violence message - 91.6\%

Enabling men to speak to men about stopping men's violence against women - $83.1 \%$

Spreading awareness of men's violence against women - $79.7 \%$

Increasing male engagement in anti-violence initiatives - $77.4 \%$

Enabling men to speak to men about gender equality and equity - $64.2 \%$

Creating a sense of community around violence prevention - $61.8 \%$

Helping to influence government policies - 54.7\%

Providing resources to men to use in their community - $49.7 \%$

Promoting research into men's violence against women $-48.3 \%$

Working with social institutions i.e., the police and military $-47.3 \%$

Integration with schools through the Breaking the Silence school program - 45.9\%

Working with sports teams $-44.3 \%$

Working with other community organisations - $32.8 \%$

Providing a safe space for men to be involved in prevention of men's violence against women - $32.4 \%$

Working with diverse communities to increase awareness and engagement - $29.1 \%$

Working with other anti-violence organisations - $24.7 \%$

Other $-5.7 \%$

Engaging workplaces - $0.7 \%$ 


\begin{tabular}{|l|l} 
UNIVERSITY \\
OF WOLLONGONG \\
AUSTRALIA
\end{tabular}

Figure A8: What do you think are areas for improvement for White Ribbon Australia? (multiple response item)

Fixed choice option

Themes identified from "Other" responses

Better communication between Ambassadors near each other - $59.5 \%$

Better use of each Ambassador's unique skill sets - $49.0 \%$

Better integration with local support services - 39.9\%

Better communication from White Ribbon Australia - 35.8\%

Better integration with women's groups - $34.8 \%$

More resources and support for Ambassadors - 33.1\%

Better culturally appropriate tools - $30.4 \%$

Less focus on "famous" Ambassadors - 27.7\%

More marketing in traditional media - $25.3 \%$

Focusing on all violence not just on men's violence against women - $23.3 \%$

More men in corporate positions within White Ribbon Australia - 18.2\%

Less focus on sport $-9.5 \%$

Different use and distribution of funds $-6.4 \%$

Other $-16.6 \%$

Integration with other groups - $2.0 \%$

More accountability and activeness of Ambassadors - 1.0\%

More training - $1.0 \%$

More support for rural Ambassadors - 1.0\%

Changes to language used by White Ribbon $-1.0 \%$

More focus on children and schools - $0.7 \%$

More focus on sport/increasing focus on sports clubs $-0.7 \%$ 


\begin{tabular}{|l|l} 
UNIVERSITY \\
OF WOLLONGONG \\
AUSTRALIA
\end{tabular}

Figure A9: What would help increase or sustain your involvement as an Ambassador? (multiple response item)

Fixed choice option

Themes identified from "Other" responses

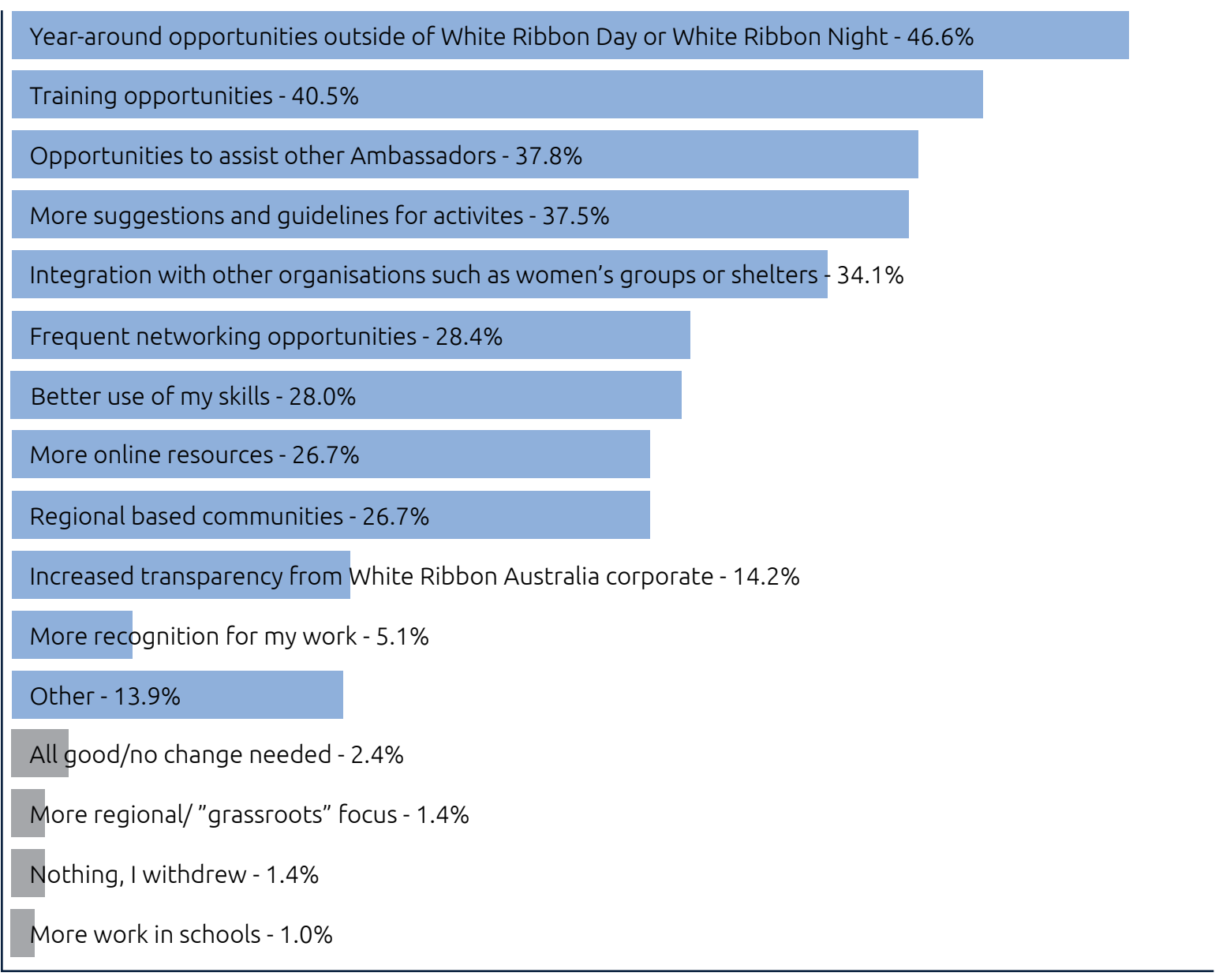

0

$50 \%$ 